\title{
Health Care Professionals Underestimate the Mean Life Expectancy of Older People
}

\author{
R. Wirth ${ }^{a, b}$ C.C. Sieber ${ }^{b, c}$ \\ a Department of Internal Medicine and Geriatrics, St. Marien-Hospital Borken, Borken, \\ ${ }^{b}$ Friedrich Alexander University Erlangen-Nuremberg, Chair of Geriatric Medicine, Erlangen, and \\ 'Department of Internal Medicine II, Nuremberg Hospital, Nuremberg, Germany
}

\section{Key Words}

Decision-making $\cdot$ Life expectancy $\cdot$ Aged $\cdot$ Aged 80 and over $\cdot$ Geriatrics $\cdot$ Elderly

\begin{abstract}
Background: The estimated life expectancy of older persons is an important component of medical decision-making. To date, no data are available on the accuracy of health care professionals in estimating the remaining life expectancy of older subjects. Methods: A survey estimating the mean remaining life expectancy of Germans of both sexes at the ages of 0,70, 80 and 90 years was performed from September to November 2010. Results: Two hundred and six health care professionals underestimated the mean remaining life expectancy of older persons by $10 \%$, on average, and with great variance $(S D=34 \%)$. Medical doctors, especially those not specialized in geriatrics, estimated worst. Conclusions: Underestimation of the remaining life expectancy of older people is prevalent in health care professionals and may lead to patients being managed inappropriately. This underscores the need for further studies and better training on this issue in health care education.
\end{abstract}

Copyright @ 2011 S. Karger AG, Base (c) 2011 S. Karger AG, Basel

0304-324X/12/0581-0056\$38.00/0

Fax +41613061234 E-Mail karger@karger.ch www.karger.com
Accessible online at: www.karger.com/ger

\section{Introduction}

Medical decisions on older patients are influenced by several factors. Besides the attending physicians' knowledge about the effect of a certain therapy, which is often not available for older patients, and their general attitude towards older people, it is their ability to accurately estimate the remaining life expectancy of such patients that might be the most decisive factor for or against a certain therapy. The decision whether to use statins in older people may be mentioned as an example. Randomized trials on the primary and secondary prevention of cardiovascular disease including older subjects, have shown a significant benefit from statins on mortality and other cardiovascular end points after a treatment period of 6 months to 3 years [1-6]. According to an evidence-based approach, statins, therefore, should be used for secondary prevention in older patients whenever their life expectancy is expected to exceed this period and if there are no contraindications, such as extensive polypharmacy [7]. In contrast, current medical practice indicates a marked underutilization of this therapy in older persons [8-10]. Thus, it has to be questioned whether this is solely due to ageism and a lack of knowledge about pharmacotherapy in the older population. Could it also be that health care

Department of Internal Medicine and Geriatrics, St. Marien-Hospital Borken Am Boltenhof 7

DE-46325 Borken (Germany)

Tel. +49 286197 3410, E-Mail rainer.wirth@ hospital-borken.de 
Table 1. Estimated $(n=206)$ and objective remaining life expectancy $(\mathrm{LE})$ and estimation error $(\mathrm{EE})$

\begin{tabular}{lcccc}
\hline Age category & Estimated LE, years & Objective LE, years & Absolute EE, years & Relative EE, \% \\
\hline Women at birth & $87.6 \pm 7.7(65-110)$ & 82.5 & $5.1 \pm 7.7(-17.5$ to 27.5$)$ & $6.2 \pm 9.4(-21.2$ to 33.3$)$ \\
Women at 70 & $14.8 \pm 4.9(3-35)$ & 16.4 & $-1.6 \pm 4.9(-13.4$ to 18.6$)$ & $-9.8 \pm 30.0(-81.7$ to 113.9$)$ \\
Women at 80 & $8.8 \pm 3.8(2-27)$ & 9.0 & $-0.3 \pm 3.8(-7.0$ to 18.0$)$ & $-3.0 \pm 42.0(-77.9$ to 198.7$)$ \\
Women at 90 & $4.9 \pm 2.5(0-18)$ & 4.3 & $0.6 \pm 2.5(-4.3$ to 13.7$)$ & $13.3 \pm 58.9(-100.0$ to 318.6$)$ \\
Men at birth & $82.6 \pm 8.3(60-107)$ & 77.3 & $5.3 \pm 8.3(-17.3$ to 29.7) & $6.9 \pm 10.8(-22.4$ to 38.4) \\
Men at 70 & $11.3 \pm 4.5(2-30)$ & 13.6 & $-2.3 \pm 4.5(-11.6$ to 16.4$)$ & $-16.9 \pm 32.7(-85.3$ to 120.1$)$ \\
Men at 80 & $6.0 \pm 3.3(1-25)$ & 7.7 & $-1.7 \pm 3.3(-6.7$ to 17.3$)$ & $-21.9 \pm 43.2(-87.0$ to 226.0) \\
Men at 90 & $3.0 \pm 2.0(0-15)$ & 3.9 & $-0.9 \pm 2.0(-3.9$ to 11.1$)$ & $-23.2 \pm 51.3(-100.0$ to 286.6$)$ \\
All subjects at birth & & & $6.5 \pm 9.9(-21.8$ to 35.8$)$ \\
Older women $(70+80+90)$ & & & & $0.2 \pm 36.4(-74.7$ to 183.9$)$ \\
Older men $(70+80+90)$ & & & & $-20.7 \pm 34.6(-84.0$ to 186.1$)$ \\
Older subjects (women and men) & & & & $-10.2 \pm 33.6(-79.3$ to 185.0$)$ \\
\hline
\end{tabular}

Data represented as mean $\pm \mathrm{SD}$ and range in parentheses.

professionals are unable to give reliable estimates of the remaining life expectancy of older patients? This could also lead to inappropriate decision-making about older patients.

To date, there are no data available on the accuracy of health care professionals' estimations of the remaining life expectancy of older patients. A large body of studies in the field of oncology indicates that physicians tend to optimistically overestimate the remaining life expectancy of patients with advanced cancer $[11,12]$. Surprisingly, there is only one small study investigating this issue beyond the domain of cancer for the general population [13] and none for the elderly.

To investigate this question, we conducted the following pilot study. Because no objective data are available on the remaining life expectancy of older patients, we asked health care professionals to estimate the mean remaining life expectancy of the general German population instead.

\section{Methods}

People in the audience of the corresponding author's lectures and seminars from September to November 2010 were asked to complete a questionnaire about their gender, age-group in decades, medical profession and specialty as well as the federal state of Germany they lived in. After that, the participants were asked to estimate the remaining life expectancy of German women and men at the age of 0, 70, 80 and 90 years. The participants were requested to give an estimate with one decimal if possible. All participants were explicitly asked not to anticipate further increases in life expectancy in the future but to assume that present life con- ditions in Germany would remain unchanged. All questionnaires were collected anonymously.

To compare the estimated data with objective data, we calculated the absolute differences in years and the relative differences in percent from actual mean age of death in Germany from 2007 to 2009 [14]. These data are shown in table 1. Data were analyzed using SPSS version 18 (SPSS Inc., Chicago, Ill., USA). Descriptive statistics were used to calculate item frequency, mean, standard deviation, median and range. The Mann-Whitney test was used to compare two groups with metric data. Group comparisons of ordinal and nominal data were performed with the $\chi^{2}$ test. Kruskal-Wallis analysis was used to compare multiple groups with metric data. A p value $<0.05$ was considered statistically significant.

\section{Results}

Two hundred and eleven participants completed the questionnaire. The questionnaires of 206 participants (34.2\% female) were sufficiently completed to be analyzed. Participants came from 8 of the 16 federal states of Germany and comprised 51 (25\%) medical doctors, 38 (18\%) medical students in their 5th year of study, 77 (38\%) nursing staff members, 7 (3\%) occupational therapists and physiotherapists and 33 (16\%) other, mostly working as nursing assistants. Eleven of 51 doctors (21.6\%) were geriatricians and $42(27.1 \%)$ of the other participants declared geriatrics as their specialty.

The estimated values and the absolute and relative differences between them and the objective values are shown in table 1. In summary, all health care professionals overestimated the mean life expectancy of newborns by $7 \%$ 


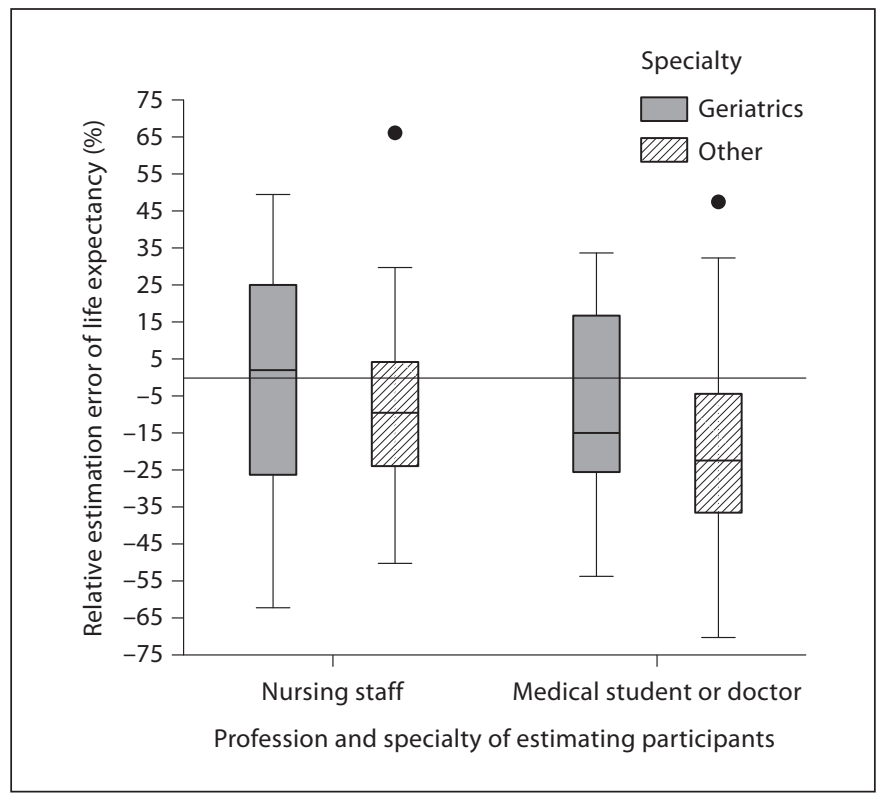

Fig. 1. Relative estimation error (\%) of the remaining life expectancy of older people (70, 80 and 90 years old), depending on the profession and specialty of the estimating subjects $(n=206$; box plots with median, interquartile range, minimum, maximum, outliers).

but underestimated the mean remaining life expectancy of older men by $20 \%$ on average. The estimation of the remaining life expectancy of older women showed inconsistent results: the life expectancy of women was underestimated by $10 \%$ for those aged 70 and $3 \%$ for those aged 80 years, but it was overestimated by $13 \%$ for 90 -year-old women.

Analysis of the estimation error of subgroups revealed that the estimating participants' age below or above 40 years had no significant influence on estimation error $(\mathrm{p}=0.352)$, nor did the participants' gender $(\mathrm{p}=0.51)$. There were no significant differences in mean under- or overestimation among the different professional groups overall ( $\mathrm{p}=0.06)$. However, comparison of medical doctors and medical students with the other participants revealed a significantly greater underestimation of the life expectancy of older people by these medical professionals compared to nursing staff ( -17.6 vs. $-4.4 \% ; \mathrm{p}=0.003$ ), while there was no significant difference between medical doctors and medical students ( -18.4 vs. $-16.6 \%$; $\mathrm{p}=$ $0.79)$ (fig. 1). In addition, participants with geriatrics as their specialty underestimated the remaining life expectancy of older people significantly less than those not specialized in geriatrics $(-2.4$ vs. $-14.1 \%$; $p=0.014)$.

\section{Discussion}

The estimated life expectancy of older persons is an important component of medical decision-making. At the present time, no data are available on how accurately health care professionals are able to estimate the remaining life expectancy of older persons. Some studies indicate that physicians tend to overestimate the remaining life expectancy of patients with advanced cancer $[11,12]$. Surprisingly, there is no study investigating this issue for the elderly. Our data demonstrate an alarming inaccuracy among health care professionals at estimating the mean life expectancy of older people. In particular, medical doctors underestimated old people's mean life expectancy to a great extent and with great variance. The most pronounced underestimation was found for older men and when the participant was not a geriatrician. In addition, the discrepancy between simultaneously overestimating the life expectancy of newborns and underestimating that of older adults is striking and prompts the assumption of a systematic misconception of the situation of older persons. The huge variance of the estimation error is most striking (table 1). More than two-thirds of all participating medical doctors substantially underestimated the remaining life expectancy. For instance, 5 doctors estimated the mean life expectancy of 90 -year-old men to be 0 years though it is actually 3.9 years in Germany. Such underestimation may lead to patients being managed inappropriately. We hope that future advances in health care education will prevent us and our older patients from being treated inappropriately by medical doctors with this misconception. Our data underscore the need for further studies and better education on this issue in health care training.

This pilot study has some limitations. The data were obtained only by the authors' peer group and are therefore not representative. This also is the reason why geriatricians were relatively overrepresented (26\%). In analyzing the data, we had the impression that some participants did not totally understand the request not to anticipate the projected prolongation of life expectancy. Some estimated a total mean life expectancy of up to 110 years. Eliminating these participants from the analysis, would have made the general underestimation we observed even worse. Another limitation is the possibility that some participants may have underestimated the life expectancy because they had their patients in mind although they were asked to the estimate life expectancy of the general population.

Future studies on this issue should focus on doctors with different specialties as the main decision makers in 
the health care system. In addition, participants who do not understand the instruction not to anticipate further increases in life expectancy might be excluded from further studies by treating the data of those who significantly overestimate the life expectancy of newborns as outliers.

\section{Conclusion}

Health care professionals, especially nongeriatricians, appear to be unable to reliably estimate the mean life expectancy of older persons, with a considerable bias to un- derestimation. This may lead to inappropriate management of older patients. Health care professionals should receive better training on this issue.

\section{Acknowledgment}

This work received no financial support.

\section{Disclosure Statement}

There is no conflict of interest.

\section{References}

1 Heart Protection Study Collaborative Group: MRC/BHF Heart Protection Study of cholesterol lowering with simvastatin in 20,536 high-risk individuals: a randomised placebo-controlled trial. Lancet 2002;360:7-22.

2 The Pravastatin Multinational Study Group for Cardiac Risk Patients: Effects of pravastatin in patients with serum total cholesterol levels from 5.2 to $7.8 \mathrm{mmol} /$ liter (200 to 300 $\mathrm{mg} / \mathrm{dl}$ ) plus two additional atherosclerotic risk factors: Am J Cardiol 1993;72:1031-1037.

3 Lewis SJ, Moye LA, Sacks FM, Johnstone DE, Timmis G, Mitchell J, Limacher M, Kell S, Glasser SP, Grant J, Davis BR, Pfeffer MA, Braunwald E: Effect of pravastatin on cardiovascular events in older patients with myocardial infarction and cholesterol levels in the average range. Results of the Cholesterol and Recurrent Events (CARE) trial. Ann Intern Med 1998;129:681-689.

4 Miettinen TA, Pyorälä K, Olsson AG, Musliner TA, Cook TJ, Faergemann O, Berg K, Pedersen T, Kjekshus J: Cholesterol-lowering therapy in women and elderly patients with myocardial infarction or angina pectoris: findings from the Scandinavian Simvastatin Survival Study (4S). Circulation 1997; 96:4211-4218.
5 Hunt D, Young P, Simes J, Hague W, Mann S, Owensby D, Lane G, Tonkin A: Benefits of pravastatin on cardiovascular events and mortality in older patients with coronary heart disease are equal to or exceed those seen in younger patients: Results from the LIPID trial. Ann Intern Med 2001;134:931940.

6 Neil HA, DeMicco DA, Luo D, Betteridge DJ, Colhoun HM, Durrington PN, Livingstone SJ, Fuller JH, Hitman GA; CARDS Study Investigators: Analysis of efficacy and safety in patients aged $65-75$ years at randomization: Collaborative Atorvastatin Diabetes Study (CARDS). Diabetes Care 2006;29:23782384.

7 Lewis SJ: Statin therapy in the elderly: observational and randomized controlled trials support event reduction. Am J Geriatr Cardiol 2004;13:10-16.

8 Bosshard Taroni W, Bula C, Darioli R Statins in older patients: limits to prescription? Rev Méd Suisse 2005;1:2512-2517.

9 Cournot M, Cambou JP, Quentzel S, Danchin $\mathrm{N}$ : Key factors associated with the underprescription of statins in elderly coronary heart disease patients: results from the ELIAGE and ELICOEUR surveys. Int J Cardiol 2006;111:12-18.
10 Niska R, Han B: Statins for secondary cardiovascular disease prevention for older primary care patients. J Natl Med Assoc 2009; 101:705-710.

11 Vigano A, Dorgan M, Bruera E, Suarez-Almazor ME: The relative accuracy of the clinical estimation of the duration of life for patients with end of life cancer. Cancer 1999; 86:170-176.

12 Clement-Duchene C, Carnin C, Guillemin F, Martinet Y: How accurate are physicians in the prediction of patient survival in advanced lung cancer? Oncologist 2010;15: 782-789.

13 Clarke MG, Ewings P, Hanna T, Dunn L, Girling T, Widdison AL: How accurate are doctors, nurses and medical students at predicting life expectancy? Eur J Intern Med 2009;20:640-644.

14 Statistisches Bundesamt: Sterbetafel Deutschland 2007/2009 (Official German statistic of survival and deaths 2007-2009). Wiesbaden, Statistisches Bundesamt, 2010 (www.destatis.de). 